\title{
Geothermal potential mapping of Northeast Morocco (Bekrane- Ahfir) using remote sensing data and GIS
}

\author{
Intissar El Morabit ${ }^{1, *}$, Soufiane Maimouni ${ }^{1}$, and Ahmed Fekri $^{1}$ \\ ${ }^{1}$ Laboratory of Applied Geology, Geomatics and Environment. Department of Geology Faculty of Science Ben M'sik Driss El \\ Harti,Hassan II University of Casablanca, Sidi Othman, Casablanca BP 7955, Morocco;
}

\begin{abstract}
Geothermal energy is part of the renewable energy mix. It is used for heating, air conditioning and sometimes even for the production of electricity. Prospecting for such a resource proves to be a difficult and capital-intensive task. To overcome this constraint, we have used remote sensing which is an adequate tool to guide the prospecting through the elaboration of hydrothermal resource potential maps at the level of zones that present a favorable potential for exploitation (hyper-tectonized sites, volcanic sites, faulted sites, sites with hot geological formations, seismic zones...). The objective of this work is to carry out a study on the North-East of Morocco (Berkane Province), in order to identify favorable sites for geothermal exploitation such as geologically and hydrogeologically active sites. The methodology adopted consists in processing the images of the OLI (Operational Land Imager) and TIRS (Thermal Infrared Sensor) sensors of the Landsat- 8 satellite in order to extract spectral indices (Clay mineral Index and Ferrous mineral Index, detecting a geothermal activity and the surface temperature map (LST) using muticriteria analysis method (MCA). ) in the north-eastern part of Morocco. The results obtained show an almost perfect concordance of the distribution of the above-mentioned indices, with the map of lineaments which are considered as heat drains from the depth to the surface. Moreover, a correct correlation was established during the validation of these results with the map of the inventory of hydrothermal springs identified in the study area.
\end{abstract}

\section{Introduction}

Geothermal energy is the heat that comes from the subsurface of the earth and generates geological phenomena on a planetary scale. It is contained in the rocks and fluids under the earth's crust and can be found as far down to the earth's hot molten rock, magma. [1],

In addition to that, there are many sites for geothermal exploitation such as geologically and hydrogeologically active sites (hyper-tectonised sites, volcanic sites, faulted sites, sites with hot geological formations, seismic zones). In order to detect these sites in a more reliable and cost-effective way, the use of remote sensing represents an efficient way in terms of time and cost.

Several methods have been developed using parameters derived from remote sensing, including spectral indices and band ratios, which are considered to be indicators of areas with favorable potential for geothermal exploration [2 - 4].

North Eastern Morocco is one of the most important geothermal fields in the country. This part of the country is also characterized by high residual magnetic anomalies related to widespread Quaternary volcanism. This is why we chose to conduct our study in this area [5].

The purpose of this study is to demonstrate that remote sensing provides initial information about the identification of sites suitable for geothermal exploitation in the Moroccan northeast, such as geologically and hydrogeologically active sites, based on the mapping of existing hydrothermal zones, hot springs [6], and surface temperature.

\section{Methodology}

This study is based on the processing and interpretation of a Landsat 8 scene which embeds two measuring instruments, the Operational Land Imager (OLI) and the Thermal Infrared Sensor (TIRS). These instruments have been designed to ensure data compatibility with older Landsat data, while benefiting from state-of-the-art technology to improve data reliability, sensitivity and quality.

The OLI multispectral imager acquires images in 9 spectral bands located in the visible, near infrared and short wavelength infrared (SWIR). Seven of these were already present on the Landsat $7 \mathrm{ETM}+$ instrument. However, the bandwidths have been refined for 6 of them. Two channels have been added: the deep blue channel, for the study of water resources and coastal areas, and an additional infrared channel for the detection of cirrus clouds. Like its predecessor ETM+, OLI provides panchromatic data at $15 \mathrm{~m}$ resolution and

\footnotetext{
* Corresponding author: intissar.al@gmail.com
} 
multispectral data at $30 \mathrm{~m}$ resolution, with a swath length of $185 \mathrm{~km}$.

It is the second instrument, TIRS, that provides thermal infrared recordings, which are now made in 2 bands instead of one. [7].

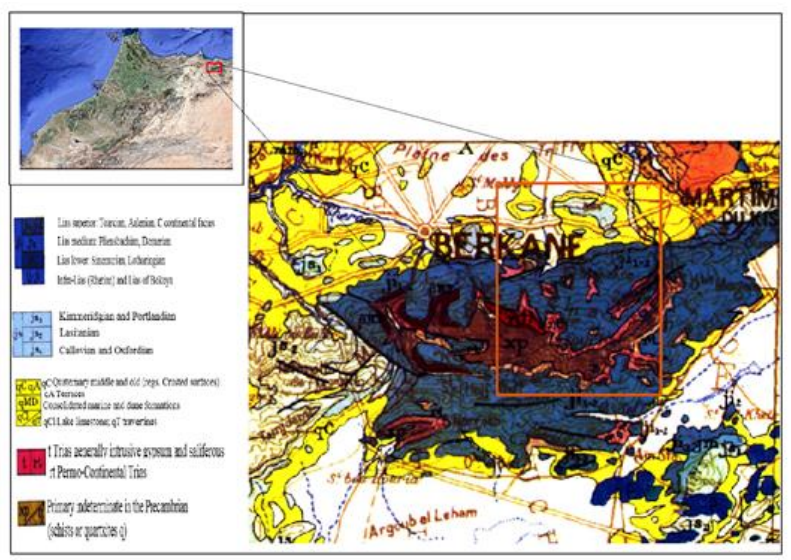

Fig 1. Geographic Location and Geological Map of the Study Area

The methodology adopted for this study is illustrated in Figure 2. It consists in processing an image from the landsat8 satellite - OLI and TIRS sensor with a spatial resolution of $30 \mathrm{~m}$ that covers the area of Brekane Ahfir, in order to extract spectral indices (Clay and Ferrous minerals) detecting geothermal activity and the surface temperature map (LST) using muticriteria analysis method (MCA). )

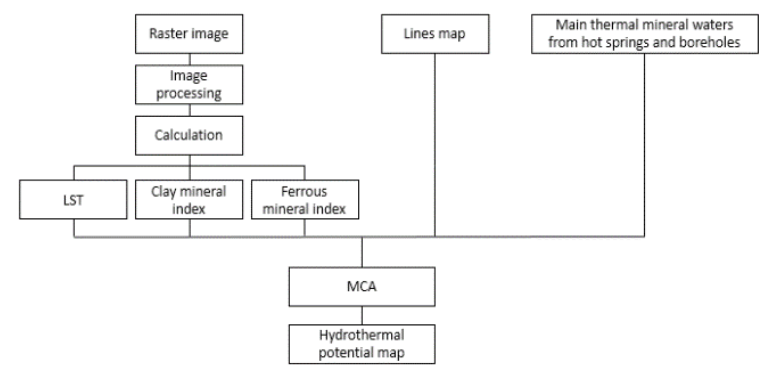

Fig 2. Organogram of the methodology

\begin{tabular}{|c|c|c|c|}
\hline \multirow{3}{*}{$\begin{array}{l}\text { Landsat } 8 \\
\text { Operational }\end{array}$} & Bands & $\begin{array}{l}\text { Wavelength } \\
\text { (micrometers) }\end{array}$ & $\begin{array}{c}\text { Resolution } \\
\text { (meters) }\end{array}$ \\
\hline & Band 1-Coastal aerosol & $0.43-0.45$ & 30 \\
\hline & Band 2-Blue & $0.45-0.51$ & 30 \\
\hline \multirow{2}{*}{$\begin{array}{l}\text { Land Imager } \\
\text { (OLI) }\end{array}$} & Band 3-Green & $0.53-0.59$ & 30 \\
\hline & Band 4-Red & $0.64-0.67$ & 30 \\
\hline \multirow{2}{*}{$\begin{array}{l}\text { and } \\
\text { Thermal } \\
\text { Infrared }\end{array}$} & Band 5 - Near Infrared (NIR) & $0.85 \cdot 0.88$ & 30 \\
\hline & Band 6-SWIR 1 & $1.57-1.65$ & 30 \\
\hline \multirow{3}{*}{$\begin{array}{l}\text { Sensor } \\
\text { (TIRS) }\end{array}$} & Band 7 - SWIR 2 & $2.11-2.29$ & 30 \\
\hline & Band 8-Panchromatic & $0.50-0.68$ & 15 \\
\hline & Band 9 - Cirrus & $1.36-1.38$ & 30 \\
\hline \multirow[t]{2}{*}{$\begin{array}{c}\text { Launched } \\
\text { February 11, } 2013\end{array}$} & $\begin{array}{l}\text { Band } 10 \text { - Thermal Infrared } \\
(\text { TIRS) } 1\end{array}$ & $10.60-11.19$ & 100 \\
\hline & $\begin{array}{l}\text { Band } 11 \text { - Thermal Infrared } \\
(\text { TIRS) } 2\end{array}$ & $11.50-12.51$ & 100 \\
\hline
\end{tabular}

Fig 3. Landsat 8 band designations

\section{Results and discussion}

\subsection{Land Surface Temperature}

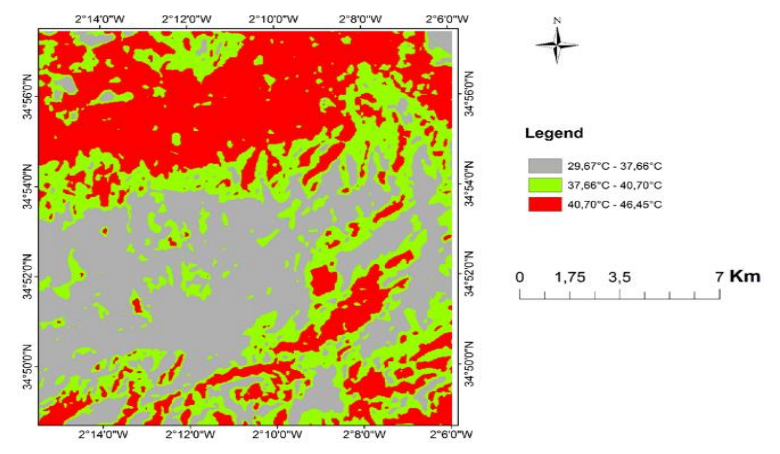

Fig 4. Land Surface Temperature map

The figure shows us a surface temperature color palette that has been classified into two classes. It was derived using the emissivity of the Earth's surface (LSE), the gloss temperature and the difference in emissivity between the LSE of the TIR bands 10 and 11 . The LST output data indicated that it ranged from $29.67^{\circ} \mathrm{C}$ to $46.45^{\circ} \mathrm{C}$. The high temperatures were mainly in the northern part of the study area. The average temperature is $38.97^{\circ} \mathrm{C}$.

\subsection{Band-ratioing of satellite imagery}
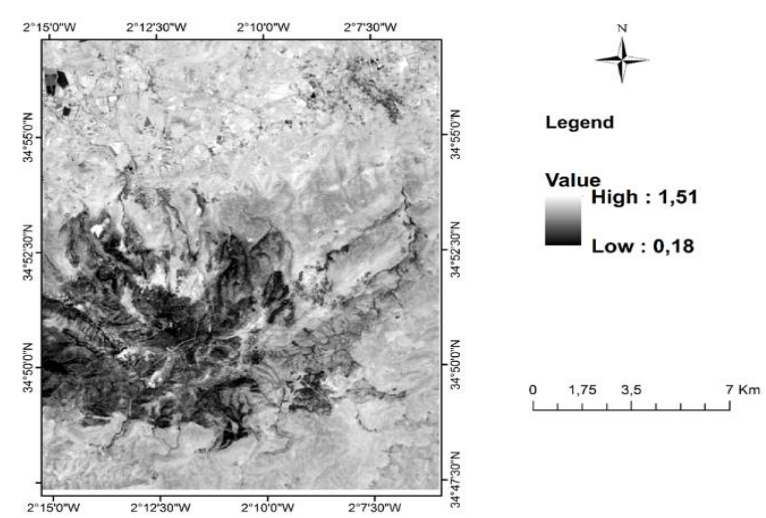

Fig 5. Clay minerals map (b7/b5)
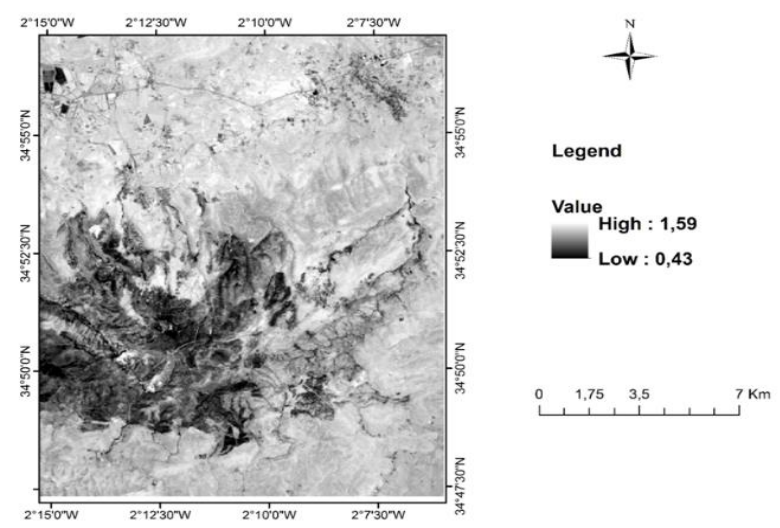

Fig 6. Ferrous minerals maps (b6/b5) 
The $6 / 5$ band ratio image shows the distribution of ferrous minerals in the region. The brightest pixels of the gray image indicate the presence of these minerals (Fig $6)$.

On the other hand, the $7 / 5$ band ratio represents the clay alteration zones of the study area. The altered rocks are in Figure 5 with brighter pixels on the image due to the reflectance characteristics of the altered rocks in band 7 and the absorption characteristics in band 7 on the Landsat8 image, this ratio is therefore considered the best ratio for mapping altered rocks.

By comparing the high showing areas with the surface temperature map, it is clear that they are superimposed on the high temperature zones $\left(37^{\circ} \mathrm{C}\right.$ to $\left.41^{\circ} \mathrm{C}\right)$.

\section{Map of the hydrothermal potential}

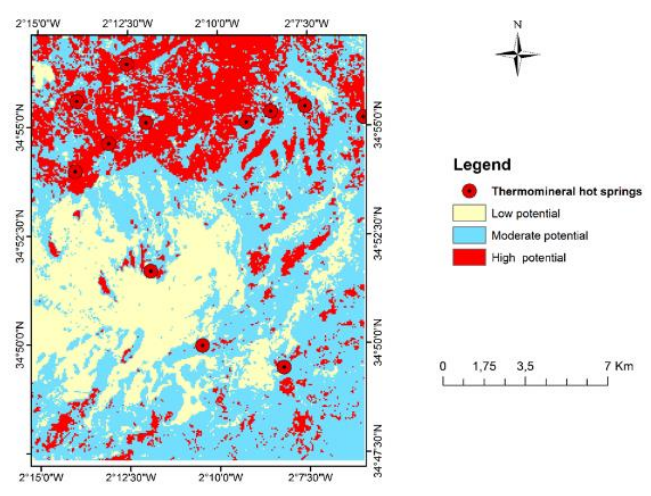

Fig 7. hydrothermal potential map

After establishing the different maps from the different scenarios made with MCA using "Overlay Weighred", we obtained a single map that meets the chosen criteria.

Although there are many works that treat the mapping of hydrothermal zones,

Although there is a lot of work that treats hydrothermal mapping, [8], few have used multi-criteria analysis as a treatment method. In fact, the latter is based on a set of procedures that allow the detailing of a decisional problem concerning complex situations. In multi-criteria analysis, one looks for a domain of resolution that can take into account all the criteria likely to influence the decision. A criterion is defined as a factor to be taken into consideration when evaluating a given scenario or assessing an opportunity for action [9].

As a method of processing our data, we used multicriteria analysis, which consists of evaluating scenarios according to a set of criteria using a structured approach. It is based on the "Overlay Weighted" method of the "Spatial Extension "Analyst" of the ArcGis 10.2.2 software. This method, which is based on the sum of weighted parameters, has been tested in various environmental studies. [10] [11] [12].

The validation of our map was done by superimposing the hydrothermal sources that we extracted from a study conducted on the same study area [3].on our resulting maps.
The red color in the map (Fig7) indicates the result of high-index maps, there is a greater chance of finding a hydrothermal site, whereas the blue and yellow colors indicate that the potential of hydrothermal zones is medium to low

\section{Conclusion}

Our study consists in the use of remote sensing via satellite image processing for the prospecting of potential geothermal resources. The eastern region characterized by a very high geothermal gradient was the subject of our application. Moreover, hydrothermal springs are a particular ecosystem and are formed by mineral deposits, sometimes in the form of ferrous and clay minerals, especially kaolinite and iron oxide.

To carry out this project, we started by calculating the surface temperature of the study area. The zones with the highest values admit linear shapes that superimpose satisfactorily with the lineaments detected by previous studies in the area. Spectral indices of the mineralogical composition of the rocks specific to the thermal zones were then used to detect zones where the presence of these indices is high. Finally, we validated the results obtained by a synthesis map of the showings by comparing it with results obtained from other studies on the same region.

However, improvements of this work are still possible by applying these methods at local scales with high resolution images.

\section{References}

1. Han, T. and Nelson, J.. BC Geological Survey. Mapping hydrothermally altered rocks with Landsat 8 imagery: A case study in the KSM and Snowfield zones, northwestern British Columbia 2015.

2. Xu. Y., Qizhong L, Yun S, Lu W. IEEE. Extraction Mechanism of Alteration Zones using ASTER Imagery.(2004).

3. A.B Pour, M. Hashim. J. Taibah Univ. Sci. Hydrothermal alteration mapping from Landsat-8 data, Sar Cheshmeh copper mining district, southeastern Islamic Republic of Iran. (2014).

4. K. Banerjee, M. Kumar Jain, A.T. Jeyaseelan, S. Panda. Curr. Sci. Landsat 8 OLI data for identification of hydrothermal alteration zone in Singhbhum Shear Zone using successive band depth difference technique - a new image processing. (2019)

5. AE Barkaoui, A Nemet, P S Varbanov, J Jr Klemeš,,Y Zarhloule , A Rimi ; Chem. Eng. Trans; Integration of Geothermal Energy in the Case of North Eastern Morocco VOL 322013.

6. AE Barkaoui, Y Zarhloule, A Rimi. Proceedings World Geothermal Congress. GIS-based Geothermal Potential Assessment for Northeastern Morocco. 2015. 
7. https://www.usgs.gov/core-science-

systems/nli/landsat/landsat-8?qt-

science_support_page_related_con $=0 \#$ qtscience_support_page_related_con

8. A. Sheikhrahimi, A. B. Pour, B. Pradhan et al., Adv in Spce Research, Mapping hydrothermal alteration zones and lineaments associated with orogenic gold mineralization using ASTER data: A case study from the Sanandaj-Sirjan Zone, Iran, https://doi.org/10.1016/j.asr.2019.01.035 2019

9. C Prévil, M Thériault, J Rouffignat. Analyse multicritère et SIG pour faciliter la concertation en aménagement du territoire : vers une amélioration du processus décisionnel ? Cahiers de Géographie du Québec, 47(130): 35-61. URI: https://www.erudit.org/fr/revues/cgq/2003-v47n130-cgq717/007968ar/) 2003.

10. M Nagarajan, S Singh Assessment of groundwater potential zones usingGIS technique. J Indian Soc Remote Sens 37:169-177. doi:10. 1007/s12524009-0012-z 2009

11. B Theilen-Willige Nat Hazard Earth Syst Sci Detection of local site conditions influencing earthquake shaking and secondary effects in Southwest-Haiti using remote sensing and GISmethods. 10: 1183-1196. doi:10.5194/nhess-101183-2010. 2010

12. B Feizizadeh, T Blaschke, L Rafiq GIS-based landslide susceptibility mapping: a case study in Bostanabad County, Iran. GI4DM conference, Antalya, Turkey 2011

\section{Appendix}

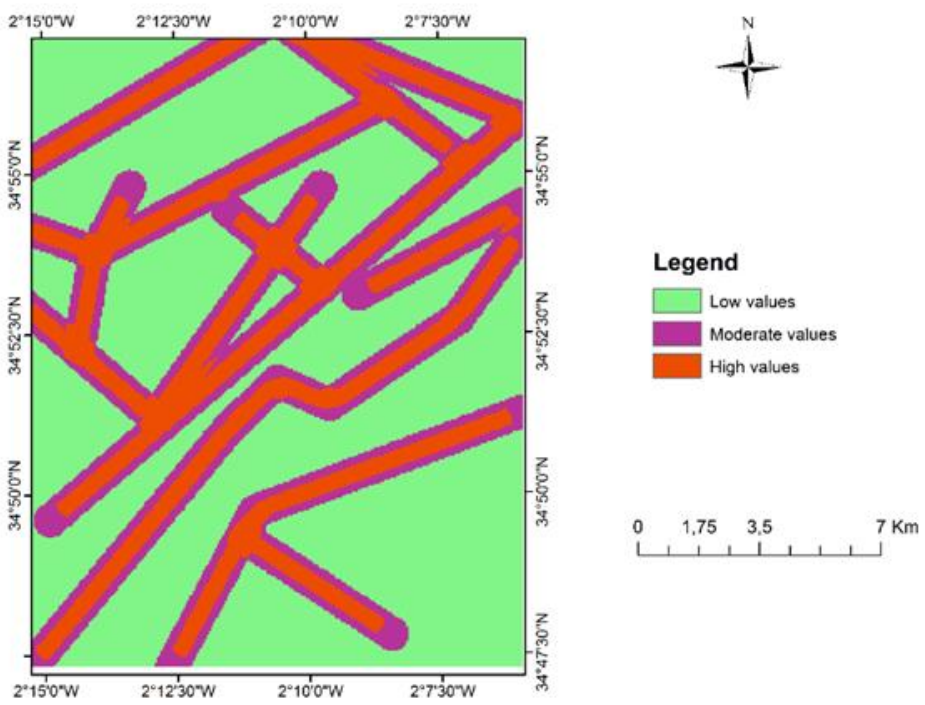

A: Lines density map

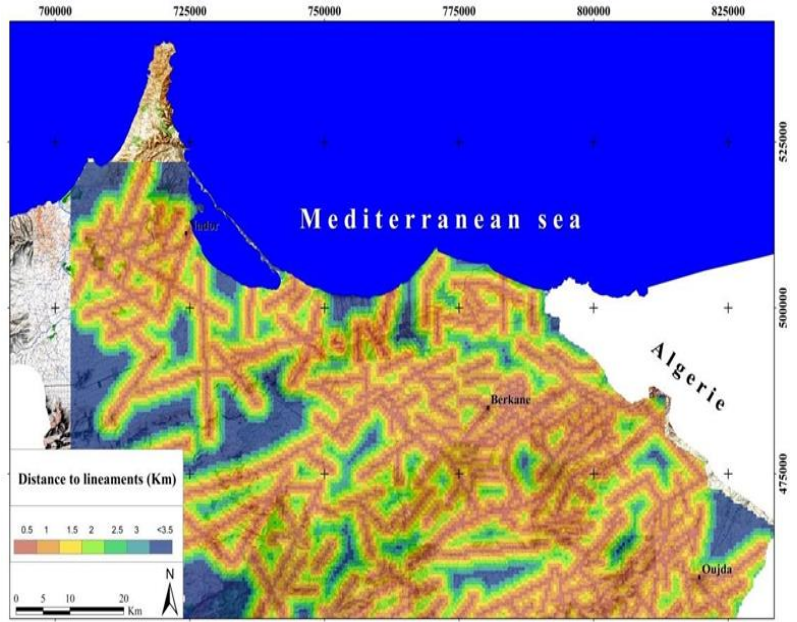

B: Map of the distance from lineaments (Km) (Berkaoui et al 2015) 